\title{
“WE'RE STILL HERE, WE'RE STILL FIGHTING.” THE EXPERIENCES OF RURAL SURVIVORS ACCESSING SEXUAL ASSAULT EVIDENCE KITS
}

by

Katelyn Bosveld, BSW, University of Waterloo, 2019

BA, University of Waterloo, 2018

\author{
An MRP \\ presented to Ryerson University \\ in partial fulfillment of the \\ requirements for the degree of \\ Master of Social Work \\ in the Program of \\ Social Work
}

Toronto, Ontario, Canada, 2020

(C) Katelyn Bosveld 2020 


\section{AUTHOR'S DECLARATION FOR ELECTRONIC SUBMISSION OF A MRP}

I hereby declare that I am the sole author of this MRP. This is a true copy of the MRP, including any required final revisions.

I authorize Ryerson University to lend this MRP to other institutions or individuals for the purpose of scholarly research

I further authorize Ryerson University to reproduce this MRP by photocopying or by other means, in total or in part, at the request of other institutions or individuals for the purpose of scholarly research.

I understand that my MRP may be made electronically available to the public. 


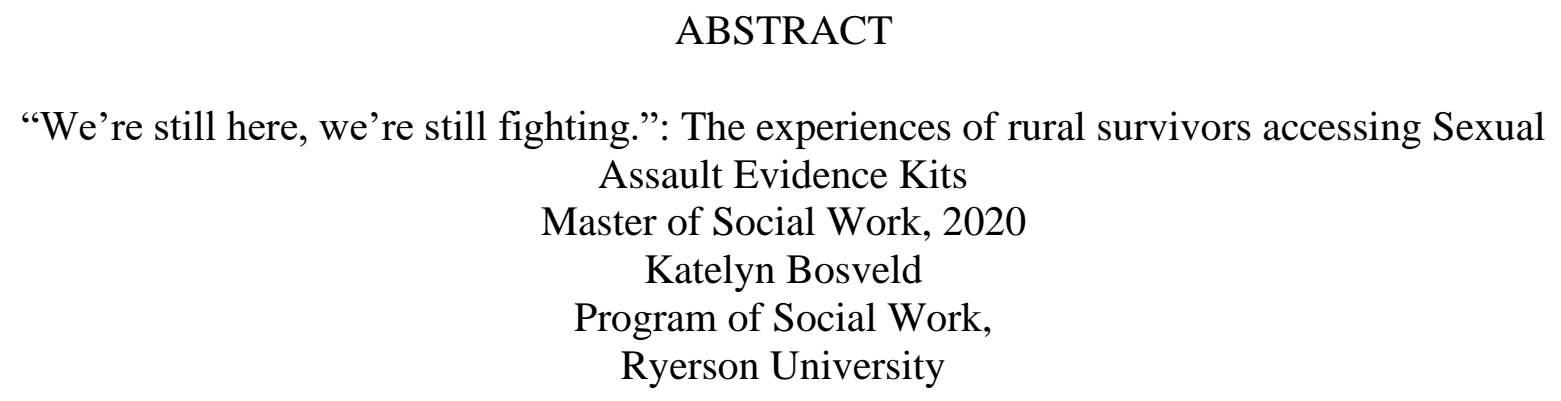

This qualitative research study explores the experiences survivors of sexual violence across rural Ontario accessing Sexual Assault Evidence Kits, as told by service providers from Sexual Assault and Domestic Violence Treatment Centres. Using a narrative thematic analysis, semi-structured interviews were completed and subsequently analyzed from an intersectional feminist perspective. The purpose of this approach was to identify themes that occurred across multiple interviews in order to understand the barriers that exist for survivors and solutions proposed by service providers in the field. Factors such as transportation, including reliance on police for transportation, are explored, as are the implications of the COVID-19 pandemic which arose partway through the research process. Additionally, implications for social work practice and service providers to survivors of sexual violence, strengths and limitations, and areas for future research are discussed. 


\section{ACKNOWLEDGEMENTS}

First, to all of the passionate participants of this study, thank you. Your dedication to your profession and the population that you serve is inspiring. Your thoughtful, critical answers reflect the genuine care that you have for survivors, and your devotion to creating a safer and more supportive experience for them. It was a privilege to learn from you. Thank you.

To my incredible supervisor, Dr. Susan Preston, for your guidance and support throughout this entire process. Your insight and perspectives are such a gift.

To my husband, Jordan, my parents, family and friends, thank you for your continued love and encouragement in my development as a social worker and researcher. I would not be here, having written an MRP and close to an MSW degree, without the faith and confidence that you have instilled and nurtured in me. Thank you! 


\section{DEDICATION}

To my incredible, strong, wonderful nieces, Hannah, Noa, and Riley:

You are my inspiration. I love you all with my whole heart, and like every good thing, I dedicate this to you.

May you grow up in a world where your gender is not a source of your oppression, but of your strength, of your community, and of your power.

And, my girls, when your privilege places your voices above the voices of others, may you highlight the voices of those who been silenced, and create space for them to be heard above your own.

I am blessed to know each of you, and to watch each step of your growth into who you are.

Love,

Auntie Katie 


\section{TABLE OF CONTENTS}

Introduction

Page \#1

Chapter 1: Theoretical Framework

Page \#4

Chapter 2: Literature Review

Page \#9

Chapter 3: Methodology

Page \#20

Chapter 4: Findings

Page \#25

Chapter 5: Discussion

Page \#50

Chapter 6: Conclusion

Page \#60

Appendices

Page \#62

References

Page \#63 


\section{LIST OF APPENDICES}

Appendix A - Interview Guide

Page \# 62 


\section{Chapter 1: Introduction}

Sexual violence, survivor rights, and the associated judicial responses continue to be widely conversed topics in present media, political, and social settings - and they are not without controversy. With issues like these becoming increasingly topical, misinformation surrounding sexual violence, rights, and trauma responses, has become increasingly widespread. "Why didn't they report?", "Why are they only speaking up now?", or the inspiration for this paper, "Why

\section{didn't they get an evidence kit?"}

To begin, Sexual Assault Evidence Kits do not exist solely to provide DNA evidence of an assault, but also to provide post-assault medical care to the survivor. Post-exposure Prophylaxis (PEP) administration, Sexually Transmitted Infection (STI) testing, and emergency contraception include some of the post-assault medical care provided to survivors to increase safety and health. Following an assault, survivor choices to complete or not complete this care are contingent on a multitude of factors, including, but not limited to, safety, access, trauma response, and relevance (Du Mont et al., 2009; Greeson \& Campbell, 2011; Johnson \& Hiller, 2019; Maier, 2012). For example, if the survivor has had recent consensual sex with the assailant, the Sexual Assault Evidence Kit may not provide any new information in terms of evidence. In fact, many Sexual Assault Evidence Kits show inconclusive results, or cannot be considered conclusive without additional context or evidence (Campbell \& Fehler-Cabral, 2018). While the public may perceive Sexual Assault Evidence Kits to be the ultimate scientific and undeniable evidence of truth following a sexual assault, in reality the situation is much less clear, as the evidence kit does not provide the full picture of the experience of the assault (Quinlan et al., 2009). What remains clear is this: blaming a survivor for not completing a Sexual Assault 
Evidence Kit fails to understand the dynamics of sexual violence and ignores the intended purpose of a Sexual Assault Evidence Kit, which is to provide care to survivors and increase their options.

While completing a practicum in a rural shelter for women experiencing violence, I was able to witness firsthand the conflicted emotions, barriers, and struggles for survivors of sexual violence accessing Sexual Assault Evidence Kits. This research paper was born out of that experience. While other factors seemed to play a significant role in the choice to attend a medical centre and often times, the rural location clearly was a factor.

Throughout the course of this research, when I tell people who have not encountered this issue before that not all hospitals in Ontario provide Sexual Assault Evidence Kits, the response is typically shock or denial. Folks simply cannot grasp that a publicly funded medical system would not have these kits widely available. Therefore, one of the intended purposes of this paper is to educate folks from a diverse range of experiences on the realities of sexual violence response in Ontario in order to allow for more understanding. Pervasive myths about sexual assault involving victim blaming or oversimplified views of systems shame survivors into silence. My hope is that a more educated view of the lived experience of accessing a Sexual Assault Evidence Kit will increase empathy and support for survivors, by reducing public stigma, shame, and victim-blaming. Together, these factors combined to result in the question guiding this research, "What are the experiences of rural survivors accessing Sexual Assault Evidence Kits, from the perspectives of service providers?"

Throughout this research process, I wanted survivor experiences to be central in everything. In an experience and subsequent system that can silence voices and diminish dignity, I wanted to provide space for all of the feelings, struggles, and pushes for change that survivors 
may have. But I also wanted to provide space for the feelings of never wanting to tell their story again, or never talking to another designated "professional" about one of the most difficult experiences of their life. So, I decided to instead interview service providers to rural survivors of sexual violence in order to reduce revictimization or re-traumatization for survivors, and to give the opportunity for service providers to speak to a variety of barriers they witness for survivors. Because service providers have interacted with many survivors, some over extended periods of time, my hope was that they would be able to identify recurring barriers and potential solutions. Through narrative thematic analysis, I was able to understand the role that rural location plays in SAEK access, by semi-structured interviewing of four participants. These are their stories. 


\section{Chapter 2: Theoretical Framework}

Due to the gendered nature of sexual violence, it is imperative to employ a feminist perspective when conducting research on this topic. Feminist inquiry seeks to understand how patriarchy and gender inequity impact the lives of women, girls, non-binary, and trans folks globally (Beckman, 2014; Falcón, 2016). Current statistics indicate that 1 in 3 women and 1 in 6 men will be sexually assaulted in their lifetime (1in6, 2020; StatsCan, 2006). Because genderbased violence and sexual violence are rooted in a perpetrator's attempts to achieve and maintain power and control, it is crucial to understand how other intersections of power are involved in this issue (Canadian Women's Foundation, 2020; StatsCan, 2006). Race, religion, income, sexual orientation, gender identity, ability, and other social and political factors impact safety and accessibility within the medical, legal, and justice systems (Canadian Women's Foundation, 2020; SACHA, n.d.). For this reason, I used an intersectional feminist perspective throughout every step of this research process.

In their book, Intersectionality, scholars Hill Collins and Bilge (2016) eloquently define intersectionality in the following way,

Intersectionality is a way of understanding and analyzing the complexity in the world, in people, and in human experiences. The events and conditions of social and political life and the self can seldom be understood as shaped by one factor. They are generally shaped by many factors in diverse and mutually influencing ways. When it comes to social inequality, people's lives and the organization of power in a given society are better understood as being shaped not by a single axis of social division, be it race or gender or class, but by many axes that work together and influence each other. Intersectionality as 
an analytic tool gives people better access to the complexity of the world and of themselves. (p. 11)

In the context of my major research paper, this approach meant seeking to deeply understand how social location impacted disclosure, access, and safety following a sexual assault, and the decision and ability to access a Sexual Assault Evidence Kit. Additionally, it meant understanding the many dynamics and factors involved not only in post-assault experiences, but what specific factors put survivors at risk of violence originally.

Hill Collins and Bilge (2016) describe intersectionality not only as a concept, but as a process and tool for analysis. In the context of my major research paper, this was used by analyzing the data in a way that searched for how factors compounded with gender to impact survivor experiences. I chose to specifically ask service providers if and how they felt intersectionality was involved in survivor experiences. I believed that this would have relevance because service providers may have insider information into who, in their experiences, has felt able to safely attend a hospital and complete a Sexual Assault Evidence Kit. For example, sexual assault service providers may notice trends from diverse populations who access their services, but do not feel that they can interact with medical or legal systems in a safe and supportive way, due to factors such as system racism, transphobia, or violence.

Within a Canadian context, having an intersectional feminist informed analysis was also crucial due to our violent colonial history and how colonial systems continue to perpetuate violence against Indigenous Peoples. As an uninvited white settler, it was vital for me to interrogate how my colonial history situated my perspectives, opinions, and views of this topic. As someone who is cisgender, heterosexual, educated, and upper-middle class, my experiences of health care have been safe, positive experiences. Prior to post-secondary education, I did not 
understand how whiteness was so entrenched in Canadian society and systems. Unlearning my assumptions and understanding how folks with identities different than mine experience medical, police, and justice systems, highlighted why it is so vital to engage in intersectional feminist approaches. By ignoring the diversity of survivors and focusing on gender alone, it is impossible to understand the whole picture of how violence is maintained using power and control.

With this in mind, and the knowledge that Indigenous women and girls experience violence at rates three times higher than non-Indigenous women and girls, and experience less police support, intervention, and investigation, it is imperative that this research be analyzed through an intersectional feminist lens (Department of Justice, Government of Canada, 2017). To specifically incorporate this element, participants were asked how intersectionality, privilege, and oppression impacted access to Sexual Assault Evidence Kits and explored how racialized survivors experienced additional barriers. However, just because an intersectional feminist lens is being used in research, that in itself does not necessarily render the research to be feminist (Beckman, 2014; Falcón, 2016). The methodology, epistemologies, and use of results must consider and embody elements of empowerment, emancipation, and activism in order to truly be recognized as intersectional feminist research (Beckman, 2014; Campbell et al., 2009; Falcón, 2016). While the details of how feminist frameworks will be operationalized will be explored Chapter 4 (Methodology), the frameworks for these steps are greatly influenced by Beckman (2014) as described below.

In their article "Training in Feminist Research Methodology: Doing Research on the Margins", Beckman (2014) outlines eight principles that must be present to guide ethical, feminist research. As much as possible, I incorporated these principles in my decision making for the methodology and frameworks of this research. 
First, Beckman (2014), states that there must be an analysis of power imbalances, and efforts to mitigate these imbalances. In the context of this research, this was done by allowing participants choice in the process, identifying the power involved, and analyzing how power imbalances impact sexual violence. Specifically this was done by incorporating consent in every level of the process, allowing participants to skip or return to an interview question, and asking participants to edit their transcriptions and approve their quotes which I have included in this Major Research Project (MRP).

Second, Beckman (2014) states that there must be an opportunity for expanding on questions. This recommendation was incorporated by applying a semi-structured interview with open ended questions, so that participants may share as much or as little as they would like. The third recommendation is to listen to the voices and experiences of women, which was central in the selection of participants and the choice to do narrative research (Beckman, 2014). Next, Beckman recommends an emphasis on diversity and intersectionality, and on the importance of mixed methods and multidisciplinary research (Beckman, 2014). This was incorporated by interviewing participants from different professional roles - both Sexual Assault Nurse Examiners and social workers - and intentionally asking how intersecting identities impacted survivors' access. Additionally, Beckman (2014) emphasizes the importance of reflexivity and of social relationships during the research process. As will be further explored, this was incorporated by the use of my personal relationship with this topic, as well as the sexual assault service provider community, to complete this research.

Lastly, Beckman (2014) explores how the results are disseminated as being at the core of feminist research methodology. By using this research to contribute to the knowledge on Sexual Assault Evidence Kit access in rural communities, survivor experiences, and the complicated 
nature of sexual violence, this research is being used with the hopes of improving the experiences of survivors, even if it is in the smallest of ways. Additionally, it hopes to contribute to a greater movement to improve the post-assault experiences of survivors and promote gender equity.

In closing, this research adopted an intersectional feminist framework, focusing on how the axis of social locations interact and impact survivor post-sexual assault experiences. As guiding principles, Beckman (2014) and Campbell's (2018) recommendations for conducting feminist research, with a specific emphasis on equity, emancipation, and empowerment, were central in both the methodology and research processes. Together, these concepts became key elements in my commitment to an ethical, informed, intersectional feminist research process. 


\section{Chapter 3: Literature Review}

My Major Research Paper topic explores and highlights the experiences of rural survivors of sexual assault accessing Sexual Assault Evidence Kits as identified by service providers who support them. Currently in Ontario, of the 262 public hospital sites, only 36 have Sexual Assault and Domestic Violence Treatment Centres (SADVTC), meaning that they have the resources and training to provide sexual assault evidence kits and post-assault care (Canadian Women's Foundation, 2020; StatsCan, 2006). This topic was born out of my own experiences both with survivorship and working in a rural shelter for women experiencing violence. My Major Research Paper involves partnering with service providers in rural communities to understand the experiences of survivors seeking Sexual Assault Evidence Kits following a sexual assault in order to address these concerns and work for change.

Following a review of recent literature on this topic, three common themes surrounding access to Sexual Assault Evidence Kits have emerged. First, I explore the survivor access and experiences with evidence collection (Du Mont et al., 2009; Greeson \& Campbell, 2011; Johnson \& Hiller, 2019). Second, I examine the Sexual Assault Nurse Examiner (SANE) administration of Sexual Assault Evidence Kits and Emergency Department responses (Du Mont et al., 2018, 2019; Du Mont \& Parnis, 2003; Johnson \& Hiller, 2019; Maier, 2012; Sievers et al., 2003). Lastly, I consider subsequent legal proceedings following a completed Sexual Assault Evidence Kit (Du Mont et al., 2018, 2019; Du Mont \& Parnis, 2003; Johnson \& Hiller, 2019; Maier, 2012; Sievers et al., 2003). As will be explored later in this paper, there were significant gaps in the research regarding the experiences of rural survivors, resulting in much of the literature focusing on urban centres and medico-legal experiences (Annan, 2011, 2014; Du Mont et al., 2009, 2018, 
2018; Du Mont \& Parnis, 2003; Greeson \& Campbell, 2011; Johnson \& Hiller, 2019; Maier, 2012; Sievers et al., 2003).

The first theme, survivor access and experiences with Sexual Assault Evidence Kits, focuses on sexual assault survivors' voices and choices (Annan, 2011, 2014; Du Mont et al., 2009, 2018, 2018; Du Mont \& Parnis, 2003; Greeson \& Campbell, 2011; Johnson \& Hiller, 2019; Maier, 2012; Sievers et al., 2003). While there is no specific research on rural location in regards to Sexual Assault Evidence Kit access, recent studies have explored survivors' reasons for delayed emergency room presentation following a sexual assault, including rural location as a barrier (Du Mont et al., 2009; Greeson \& Campbell, 2011; Johnson \& Hiller, 2019; Maier, 2012). In addition to this variable, other factors such as relationship to the perpetrator, community access to sexual assault services, and identifying as racialized or Indigenous were noted as reducing attendance in emergency departments (Johnson \& Hiller, 2019).

Beyond access, the way in which survivors experience and engage with the Sexual Assault Evidence Kit process shows where gaps in services, and the kit itself, can fail to support survivors of sexual assault (Du Mont et al., 2009; Greeson \& Campbell, 2011; Maier, 2012). Interviews with survivors of sexual assault and Sexual Assault Nurse Examiners reveal that these kits have the potential to revictimize survivors, as they are invasive, time consuming, and deeply personal (Du Mont et al., 2009, p. 200; Greeson \& Campbell, 2011; Maier, 2012). In contrast to these feelings of revictimization, survivors also stated that they felt empowered by their choice to complete a Sexual Assault Evidence Kit and they felt the Sexual Assault Nurse Examiner was competent and compassionate in providing their care (Du Mont et al., 2009; Greeson \& Campbell, 2011; Maier, 2012). Additionally, survivors stated that they felt as though they were holding their assailant accountable for their actions (Du Mont et al., 2009; Greeson \& Campbell, 
2011; Maier, 2012). This research briefly highlights the experiences of survivors of sexual assault accessing Sexual Assault Evidence Kits, but also reveals the significant need for more research that focuses specifically on rural survivor voices.

The second theme, Sexual Assault Nurse Examiner administration of Sexual Assault Evidence Kits and Emergency Department response explores the competency of medical professionals to respond appropriately to survivors of sexual assault (Du Mont et al., 2009, 2018, 2019; Du Mont \& Parnis, 2003; Maier, 2012; Sievers et al., 2003). These studies have identified the unique set of training and skills that Sexual Assault Nurse Examiners have that equips them to more accurately, compassionately, and critically conduct Sexual Assault Evidence Kits (Du Mont et al., 2009; Du Mont \& Parnis, 2003; Maier, 2012; Sievers et al., 2003). Survivors receiving post-sexual assault medical care from Sexual Assault Nurse Examiners report receiving higher quality care than those who received care from nurses who are not trained as Sexual Assault Nurse Examiners (Du Mont et al., 2009; Du Mont \& Parnis, 2003; Maier, 2012; Sievers et al., 2003). This research also showed that Sexual Assault Nurse Examiners were able to draw from their experience to identify which questions and procedures in a Sexual Assault Evidence Kit were considered necessary or not, based on the nature of the assault (Du Mont \& Parnis, 2003). This critical engagement with the Sexual Assault Evidence Kit helped to reduce survivors experiencing unnecessary, invasive medical care (Du Mont \& Parnis, 2003).

This research aligns with the consistent evidence that Sexual Assault Nurse Examiners are better equipped than non-Sexual Assault Nurse Examiners and Emergency Department staff to perform Sexual Assault Evidence Kits, based on both conduct and accuracy (Du Mont et al., 2009; Du Mont \& Parnis, 2003; Maier, 2012; Sievers et al., 2003). This is believed to be due to the lack of training that medical professionals and Emergency Departments receive on 
supporting survivors of sexual assault (Du Mont et al., 2018). Interventions to increase capacity and skills of emergency department staff in responding to survivors of sexual assault have shown to be effective (Du Mont et al., 2018). Despite the high quality of care that Sexual Assault Nurse Examiners provide, there are significant limitations and an evident need for future training in supporting trans survivors of sexual violence (Du Mont et al., 2019). In a recent study by Du Mont et al. (2019), it was found that $73 \%$ of Sexual Assault Nurse Examiners stated that they had little to no expertise in providing Sexual Assault Evidence Kits to trans survivors, and 95\% indicated that they would benefit from additional training.

The third and final theme that arose from this review of the literature is the legal experiences of survivors and advocates following a Sexual Assault Evidence Kit (Annan, 2014, 2011). Legal advocates describe discrepancies in jury perceptions of Sexual Assault Evidence Kits, as they often see DNA evidence as necessary for a guilty verdict (Annan, 2014). However, DNA evidence does not determine if consent was given or not (Annan, 2014). For example, in cases where the assailant was an intimate partner, it is highly plausible that DNA evidence is present due to previous consensual sex, but that does not change that a sexual assault has occurred (Annan, 2014). Because of this lack of understanding about the meaning of present DNA and the purpose of Sexual Assault Evidence Kits, arrests, charges, and conviction rates for sexual assault continue to be very low, with approximately $12 \%$ of cases reported to police resulting in a conviction (Annan, 2014, 2011).

Collectively, these three themes provide a guide to understanding the current research that exists on rural access to Sexual Assault Evidence Kits (Annan, 2014, 2011; Du Mont \& Parnis, 2003; Du Mont et al., 2018, 2009; Greeson \& Campbell, 2011; Johnson \& Hiller, 2019; Maier, 2012; Mont et al., 2019; Sievers et al., 2003). They reveal the gaps and biases that exist 
currently, which assists in my future research and the future research of others, to explore these gaps further and question the current research that exists.

Through investigation into the theoretical frameworks and epistemological paradigms of these studies, it was clear all of the research was conducted from a feminist perspective. These articles recognized the gendered nature of sexual violence, and their goals in conducting this research were to advanced the rights of survivors by providing agency, advocacy, and understanding of gender-based violence to service providers (Annan, 2011, 2014; Du Mont et al., 2009, 2018, 2019; Du Mont \& Parnis, 2003; Greeson \& Campbell, 2011; Johnson \& Hiller, 2019; Maier, 2012; Sievers et al., 2003). However, using a gender-based, or even stated "feminist" perspective does not automatically create feminist research, as epistemology is reflected in methodology (Beckman, 2014; Carter \& Little, 2007; Denzin, 2017; Falcón, 2016). While some of these studies claim to be feminist, by failing to locate themselves, critically dissect gender-based power imbalances, include an intersectional lens, or engage in relationship with the participants, these studies reproduce and maintain white, cisgender, heterosexual feminism (Beckman, 2014; Falcón, 2016).

In addition to feminist epistemologies, the majority of these articles were written from positivist, neoliberal paradigms and theoretical frameworks, as evident by their use of statistics, 'experts' and stated 'objective' research stances (Carter \& Little, 2007; Denzin, 2017). This was not surprising as all of the research was conducted in medical or legal systems, which focus on evidence-based practices and promote quantitative research as the standard for knowledge production. While some articles, such as Du Mont (2008) and Greeson and Campbell (2011) resisted this expectation and interviewed survivors directly about their experiences in order to initiate changes in their fields, the majority of articles did not frame survivor voices, choosing to 
focus on legal or medical professionals without identifying a purpose for this exclusion, such as avoiding revictimization of survivors.

There are significant limitations, but also understood strengths to the approaches of the existing knowledge on this topic. Personally, through critical inquiry, I identified significantly more limitations than strengths within this research. However, I do acknowledge that despite having weaknesses, some of this research has been used positively to promote the rights of survivors of sexual assault, for which I am grateful.

A notable limitation of these articles, based on positivism, is the assertation that knowledge can be unbiased and externally valid (Carter \& Little, 2007; Denzin, 2017). Through analysis, it is evident that all of the articles had predominantly white, western, heterosexual participants, which is not representative of the diversity of survivors of sexual violence, and fails to acknowledge the intersections of race, ethnicity, gender identity, class, ability, or Indigeneity with sexual violence. Notably, one study does focus on the experiences of trans survivors of sexual assault, however trans voices are not included (Du Mont et al., 2019).

By choosing not to interview survivors directly and to focus instead on the opinions of legal advocates and medical responders, this research reduces survivors to numbers and statistics, and fails to reflect their voices and experiences. In a situation where they have been silenced, research has further silenced their voices. How isolating does it feel to interact with colonial, Western systems following an invasive and traumatizing assault? How violating does it feel to have to out oneself as trans person to a nurse who has no experience or training on administering a Sexual Assault Evidence Kit to trans survivors? What are the cultural barriers? Where is the resistance and agency? These are questions that quantitative research leaves unanswered, and that I hoped participants would explore in their responses to my interview questions. The 
answers to open-ended questions similar to these provide rounded insight into the experiences of survivors.

Due to the highly invasive and sensitive nature of this topic, I can understand why some researchers would choose not to speak directly to survivors, as a conscious attempt to avoid revictimization. Personally, this is what I chose to do, but with a critical consciousness and intention that will be explored later in this paper. However, these researchers did not state that they intentionally interviewed service providers to avoid revictimization of survivors, but instead operated from the framework that medical professionals and legal advocates had more expert opinions on this topic - this is where the limits to the action lie. There are strategic ways in which researchers could avoid revictimizing survivors and placing the responsibility for change onto them, while still highlighting their voices and experiences; however, most of the researchers chose not to attempt this.

As previous mentioned, much of the existing knowledge on this topic is quantitative in nature and was conducted through observation, pre and post intervention surveys, Likert scaled surveys, and Sexual Assault Evidence Kit audits (Du Mont et al., 2018, 2019; Du Mont \& Parnis, 2003; Johnson \& Hiller, 2019; Maier, 2012; Sievers et al., 2003). In contrast to this, some researchers did choose qualitative methodologies, all of which conducted interviews (Annan, 2011, 2014; Du Mont et al., 2009; Greeson \& Campbell, 2011). Notably, Annan (2011, 2014) was the only researcher who chose to state and explain their purposeful methodology, and used hermeneutic phenomenology, which guided their research with sexual assault service providers and legal advocates.

These research methods were limited not only in terms of results, but also in participants, because the survivors, medical professionals, and legal advocates who are most easily accessible 
to interview are not always representative of the full diversity of the survivor community, because they experience the most safety, protection, and support (Annan, 2011, 2014; Du Mont et al., 2009, 2018, 2019; Du Mont \& Parnis, 2003; Greeson \& Campbell, 2011; Johnson \& Hiller, 2019; Maier, 2012). Due to the highly stigmatized, medicalized, and legalized colonial processes that follow a sexual assault, and the discrimination that exists in these systems, sexual assault reporting, in both medical and legal settings, is consistently very low (Annan, 2011, 2014; Du Mont et al., 2018, 2019; Du Mont \& Parnis, 2003; Greeson \& Campbell, 2011; Johnson \& Hiller, 2019; Maier, 2012). As a result, all research conducted with survivors of sexual assault is going to be highly disproportionate in its representation of the diversity of survivors of sexual assault. This is because such research has focused on survivors from privileged identities who have the transportation, support, and perceived credibility to safely access medical and legal systems following a sexual assault (Annan, 2011, 2014; Greeson \& Campbell, 2011; Johnson \& Hiller, 2019). When completing my Major Research Paper, this is something that I plan to intentionally address and formally recognize as a significant limitation. Specifically in relation to my MRP topic, with evidence that rural survivors of sexual assault are less likely to receive medical care, it will impact which survivors my participants support and see in their work (Annan, 2011, 2014; Johnson \& Hiller, 2019).

Examining this literature has given me an understanding of existing knowledge on my MRP topic but has also provided me with much to reflect on in terms of what to do differently in my own research. To begin, I want to locate myself within this research as a survivor of sexual violence, while recognizing that my identity as a white, cisgender, heterosexual woman who experiences economic and social privilege, and that my experiences with sexual violence are not 
reflective of most survivors. Because of this, I need to engage in reflexive practice and be critical with my analysis and data collection to present the results in sensitive and representative ways.

I want to critically engage with the aspects of authentic feminist epistemologies, which Beckham (2014) identifies as the "Eight Principles of Feminist Research". These principles focusing on power imbalances, expanding on questions, listening to women's voices, emphasis on diversity and intersectionality, multidisciplinary and mixed methods research, reflexivity, social relationships during the research process, and use of results - are all vital guidelines to ensuring that the research process connects with feminist epistemologies (Beckman, 2014).

With intention, I am choosing to interview rural service providers for survivors experiencing violence, asking about their collective experiences in supporting survivors of sexual violence in accessing Sexual Assault Evidence Kits instead of speaking directly to survivors. I am critically choosing to do this because I have pre-existing relationships with rural service providers in Southern Ontario and believe it would be re-victimizing and unethical for me to collect data from survivors with whom I do not have a pre-existing relationship. I understand that this decision to focus on service providers rather than survivors creates limitations in my results, but this is something I have chosen to do to prevent further harm to a community that has experienced such significant violence. I also recognize the intersection that many service providers to women who have experienced violence are themselves women who have experienced violence (Barter, 1997; Gore \& Black, 2009; Thomas, 2016; Ulloa et al., 2016). Because of the high correlation of service providers having had personal experiences of sexual violence themselves, I am choosing to formulate my interview questions and research around recommendations by survivors of sexual assault, as assembled by Campbell et al. (2009) (Gore \& Black, 2009; Thomas, 2016; Ulloa et al., 2016). These principles include: representing 
diversity, creating opportunities for choice and control, and demonstrating warmth and compassion (Campbell et al., 2009).

Service providers who work in gender-based violence fields may strengthen the research by being able to speak to their experiences supporting survivors of sexual assault who did not choose to interact with medical or legal systems, and how they were able to support that highly vulnerable population. This may give insight into changes that must be made in order to increase access to all survivors, or provide alternative options to ensure that, should survivors not want to interact with colonial systems, they can still experience the medical care that may be required following a sexual assault (i.e., post-exposure prophylaxis, sexually transmitted infection testing, and emergency contraceptive) and be provided with competent, quality care by a compassionate and trained nurse. Ultimately, my intention in this process is to place the expertise, decision making, results in the hands of participants. This was done by giving open ended questions, allowing them to select which quotes were appropriate to include, and asking them in the interview if there was anything that they felt was missed and should be included.

When recruiting participants, I sought a diverse selection of folks who represent multiple communities and hold intersecting identities. Much of the research existing on this topic failed to do this, which is why there is such significant gaps. Additionally, when conducting my literature review, I searched for articles that focused on the voices of survivors, those who support them, and stories of their experiences. This helped provide a more rounded view of the issue and the many factors involved. After completing the data collection process, I shared the results with participants to promote them feeling that they have been accurately represented; I then made any necessary changes as a result. 
The purpose of this research is to highlight the voices of this community to contribute to change and improve access to Sexual Assault Evidence Kits for survivors who want and choose to complete them, and to never encourage folks who have actively chosen not to complete Sexual Assault Evidence Kits to influence their decision to do so. This is about choice and access, not about control, manipulation, or coercion to engage in colonial systems that require quantitative physical evidence following an assault, in addition to being systemically embedded with violence and discrimination.

By reviewing this literature, I was able to see where researchers have mobilized communities and created positive change for survivors, but also where they have silenced the survivor community or failed to accurately represent them. This has provided me with the opportunity to reflect upon and engage with how my Major Research Paper could be conducted differently in order to be embedded with feminist epistemologies. This practice of reflexivity and critical analysis being integrated into the research process has been central to my entire MRP process and will continue to be so in my subsequent social work practice. 


\section{Chapter 4: Methodology}

The methodology of this research focused specifically on feminist principles and was executed in a thematic narrative analysis format (Nowell et al., 2017). In overview, semistructured interviews were conducted with service providers who support survivors of sexual assault about their experiences supporting survivors and barriers to access that they had identified, which were later analyzed to identify themes, ideas, similarities, and differences between the suggestions, perspectives, and experiences of the participants.

This research was born out of my own experiences during a ten-month practicum at a rural shelter for women experiencing violence. During that time, I became aware that the local hospital did not provide Sexual Assault Evidence Kits, and that the nearest Sexual Assault and Domestic Violence Treatment Centres were over an hour away. Unfortunately, we did not have the funding to provide transportation to these hospitals, and they did not offer mobile services. Because of this, survivors were left to arrange child care, transportation, and/or time off of work themselves in order to go to distant hospitals for lengthy, invasive Sexual Assault Evidence Kits.

Among the agency employees and students, there were conversations about what could be done differently in order to increase the availability of these kits and training for Sexual Assault Nurse Examiners. Out of this, my MRP topic was born. I felt a deep desire to understand if this was happening in other rural communities as well, why it was happening, and how it could be solved. This process highlights for me the need for collaborative service provision, expanded access, and creative problem solving.

To begin, I contacted the rural women's shelter where I attended practicum for a letter of support for this research. I was intentional in clearly stating they were in no way obligated to participate in this research, that participants' involvement was entirely voluntary, and that they 
may remove their involvement at any time without impacting their relationship with myself or Ryerson University. They provided a letter of support for this research, outlining why they felt it was necessary and how it could potentially benefit the survivor and service provider community. This letter was incorporated in the submission to the Ryerson Research Ethics Board.

After receiving Research Ethics Board (REB) approval, I contacted the Executive Director of this shelter to begin recruitment. The Executive Director supported the process of snowball sampling (Biernacki \& Waldorf, 1981). In doing so, my recruitment email and accompanying poster was forwarded to other rural agencies that support survivors of sexual assault. Next, these emails/posters were sent from directors of the organizations to all staff, so that any eligible and interested participants could contact me.

I was intentional in my choice to select snowball sampling as a recruitment method because of the high levels of confidentiality involved when supporting survivors of sexual violence (Biernacki \& Waldorf, 1981). When dealing with such sensitive matters, there is a high level of fear among agencies that a researcher may not fully understand the factors involved, may look poorly upon the agency, or may present the findings in a way that is not supportive of the agency's work. By having the support of this shelter, a message was inferred to potential participants that this research is coming from the inside, and the researcher has a theoretical framework that is consistent with the field (Biernacki \& Waldorf, 1981). By doing this, I greatly increased my chances of having enough participants to complete this research, and of creating a trusting participant and researcher relationship (Beckman, 2014; Biernacki \& Waldorf, 1981).

I encountered an interesting dilemma in recruitment timing, as my materials were sent out in mid-April of 2020, during the COVID-19 pandemic lockdown. As will be discussed later, this pandemic created increases in family violence, which significantly impacted shelters and 
services to survivors, who were considered essential workers. For the first few weeks of recruitment, I did not receive any responses. However, after about four weeks, I began receiving consistent responses. Two shelters had responded that they had forwarded my recruitment materials to their nearest Sexual Assault and Domestic Violence Treatment Centres and suggested that I send my materials directly to them, as I may receive more responses at this time. Given that I had REB approval to send the materials directly to any service providers to survivors of sexual violence, I began the process of sending the materials directly to rural Sexual Assault and Domestic Violence Treatment Centres that service rural populations or large catchment areas.

Prior to the COVID-19 pandemic, the intended process for my research process was that after receiving my recruitment email and flyers, participants contacted me via my Ryerson email address to arrange an interview time and location. The conditions of my eligibility criteria were that the participants must be located in rural Ontario and I planned to use my Ryerson Graduate Scholarship funds to travel to these communities. In our email interactions, I would communicate with participants to identify local locations where they would be most comfortable for their interview. Locations would include private rooms in public locations, such as community centres or public libraries, so that both confidentiality and safety would be best maintained.

Due to the COVID-19 pandemic, the format of the interview changed to be conducted digitally, as face-to-face interviews were not safe due to the risk of virus transmission. This adaptation resulted in an additional inclusion criterion that the participant must have a private space to complete the interview. Because of this change, the interviews were done over video or 
audio calls on Zoom, depending on the participant's preference. To reduce the risk of identifying the participant, only the audio was recorded from these calls.

The interviews were semi-structured and followed the interview guide listed in Appendix A. They were recorded on a password protected iPhone and transcribed onto a password an encrypted Ryerson Google Drive within one week of the interview, at which time, the audio recording was deleted. At the time of the interviews, the participants were provided with a list of gender inclusive names to pick as a pseudonym. This pseudonym was used in all subsequent communication and in the data analysis process. After transcription, the password protected transcribed interview was sent to the participant for their approval. Through the consent form and as reviewed during the interview, participants were aware that they had one week from the date that they received the transcription to send their revisions, withdrawal, or approval. The purpose of this approach was to provide participants with an active role throughout this process, and to optimize their choice, voice, and autonomy in the research (Beckman, 2014). I wanted their interviews to reflect their narratives, experiences, and stories as accurately as possible, so it was vital that these were portrayed how they wished, with their maximum involvement (Beckman, 2014).

After this time, the interviews were shared with my Major Research Paper supervisor and I began the data analysis process. I used a narrative thematic analysis to analyze the findings of these interviews (Nowell et al., 2017). This was based on six specific phases outlined by Nowell et al., (2017), in order to ensure that the research was rigorous, thorough, and credible.

To complete Phase 1: Familiarizing yourself with the data, I collected all transcribed interviews and conducted close readings to gain familiarity, comfortability, and understanding of the data available (Nowell et al., 2017). Next, for Phase 2: Generating initial codes, each 
transcribed interview was thoroughly analyzed for statements or phrases that were appeared to be substantial, meaningful, or recurring (Nowell et al., 2017). Each statement that was similar across interviews was highlighted in the same colour, and variations of a similar theme were indicated by changes in that shade of colour. For each new theme, a new highlight colour was used - this completed Phase 3: Searching for themes (Nowell et al., 2017).

Next, after each document was colour coded, I created a new document where all similar words, statements, and phrases, were listed together in their corresponding highlighted colour. I then considered what made them similar and identified that as the theme. This process completed Phase 4: Reviewing themes (Nowell et al., 2017). After repeating this process with all highlighted colours, four themes were identified.

Next, I completed Phase 5: Defining and naming themes, where I analyzed the emerging themes to identify major, guiding themes that were strongly evident in the interviews (Nowell et al., 2017). Through this narrative analysis, several major themes were identified, as noted in the next chapter.

After identifying these themes, I explored them further in the "Findings" and "Discussion" portions of this paper, to complete Phase 6: Producing the report (Nowell et al., 2017). In this section, themes were analyzed in accordance with the theoretical framework, as well as supported with current literature on this topic. Each participant's story is told in a tangible, thematic way, to support an understanding the gravity of this issue, the factors involved, and potential resolutions and implications. 


\section{Chapter 5: Findings}

\section{Introduction}

With the contributions of critical, deep, and thoughtful interviews with participants Jade, Quinn, Charlie, and Ash, all of whom work in Sexual Assault and Domestic Violence Treatment Centres that support survivors in rural Ontario, I was able to identify four clear themes through the use of thematic analysis. These themes are broad in nature because they encompass many individual experiences and subthemes.

The first is "Rural Realities". This theme explores how aspects of residing in a rural location contribute to it being a unique and distinct factor in the inaccessibility of Sexual Assault Evidence Kits. The second is "Intersections, Systems, and Safety", which examines the way in which folks with diverse identities experience additional barriers to accessing Sexual Assault Evidence Kits due to medicalization, police presence, and discrimination. The third is "Implications of COVID-19 Pandemic", which explores how the current circumstances of mandated social distancing and quarantine, and fear of contracting the virus compound to reduce access to services for survivors. Lastly, the fourth theme is "Resilience, Resistance, and Transformation", which explores how the survivor community has shown resilience through this inaccessibility by identifying and implementing solutions; further suggestions by service providers are also explored.

The participants in this study represented a diverse population of professionals from various rural locations across Southern and Northern Ontario, each working in a Sexual Assault and Domestic Violence Treatment Centre located within a hospital. Jade is a Registered Social Worker, while Charlie, Quinn, and Ash are Registered Nurses who trained as Sexual Assault Nurse Examiners. This distinction qualifies them by the Ontario Network of Sexual Assault and 
Domestic Violence Treatment Centres to conduct Sexual Assault Evidence Kits and other medical forensic care with a level of accountability to expertise, training, and trauma-informed care. The time spent in their respective roles ranged from 2 to 25 years. The participants were all located within hospitals from Northern and Southern Ontario that served large catchment areas of rural survivors and smaller community hospitals that do not conduct Sexual Assault Evidence Kits. Each participant contributed their own unique experiences within the field of sexual assault services to this research.

In contrast with some forms of narrative analysis, the number of direct quotes in this paper have been reduced out of an abundance of caution for the confidentiality of participants. There are only 36 Sexual Assault and Domestic Violence Treatment Centres in Ontario, and only a small number of those serve rural populations. They operate on relatively small teams, and I wanted to exercise extreme caution with any information that could potential identify the area, and subsequent team, that the participant was on. For this reason, language surrounding which participant gave which responses, and the general geographic population that they may serve, is very vague.

While each story and each perspective were unique, common themes flowed through their narratives of times of perseverance, determination, and advocacy for survivors. If there is one point that connects all four of the themes perfectly, it is how barriers compound to remove access to care. One quote from a participant, Quinn, struck me in a way that it influenced how I viewed the data from this research: "There are so many barriers in general for accessing services for sexual assault or domestic violence. There are so many barriers that already exist, and being in a rural location simply compounds that." 


\section{Rural Realities}

The first theme that emerged, and aligned most with the research question, was "Rural Realities", which focuses on the distinct barriers that rural survivors face when accessing Sexual Assault Evidence Kits. Well documented barriers, such as a lack of access to personal transportation and a subsequent reliance on police to provide transportation, are explored. Additionally, obstacles specific to participants' locations, or barriers have not been heavily documented in research, such as the importance of community partners for referrals and training and capacities of small community hospitals, are dissected.

The most commonly cited barrier was the issue of transportation to hospital. Every participant named this as the first and most significant barrier that is specific to rural survivors and the factor that most complicates access. Despite having different sizes of catchment areas and variation in subjective rurality, each participant identified this. Participant Ash explained "We're a big catchment area and I would say the biggest challenge that's been identified is travel. Because there's travel involved in getting them to a higher level of care." This was echoed by Charlie, who, when asked what challenges survivors encounter in accessing care, stated “There's a lot of clients, especially rural, that have a difficult time transportation wise." The other participants, Jade and Quinn, also responded with "transportation" when asked what they believed to be the top barrier to access.

For survivors who do not have access to a vehicle, driver's license, or are too young to drive, attending a hospital that could be up to two hours away is not an option without disclosing to a support person with a vehicle, or contacting police. As will be discussed further in the research, this reliance on police to transport removes the survivor's choice in involving police if they want medical care and creates an additional barrier for survivors whose safety is jeopardized 
by interacting with police. Participant Charlie explained how this experience comes to be, and also the contrast in responses from police versus Sexual Assault and Domestic Violence Treatment Centre staff explaining, That's another thing too, fear of police. Some people who are homeless, for example, or don't have a lot of resources, or use substances, or are being trafficked and they don't want to be judged, or they've been turned away from police, or they are not believed. We do get people who are more vulnerable and we tell them right off the bat - "We're not here to judge you, we're here to help you. What is it that you need? What would work for you?"

This barrier was also explained by Ash, who explained,

If transportation is an issue to get here from our rural hospitals, sometimes police may be involved when the person doesn't want police involved. So that could definitely be a barrier, having to have police involvement in order to receive care ... There tends to be more involvement with rural survivors. So, my worry is that people who don't want police involvement aren't getting care.

When understanding the barrier of transportation, it is crucial to recognize that the most significant barrier in survivors accessing Sexual Assault Evidence Kits is physically getting to a hospital that can provide them with one, along with other specialized post-sexual assault care. When their local community hospital does not provide this care and fails to tell them upon arrival or facilitate a transfer, survivors can feel abandoned, unsupported, and settle for reduced quality of care. Participant Quinn explained this process and how it impacts survivors' autonomy and choice in their care, saying, 
That's kind of the first barrier, that they have to get to us. The second barrier is that they are often presenting to their community hospital first. So they've already waited in the hospital, in the emergency department for who knows how many hours to be triaged, only to be told "We can't help you here. Your next option is to go to (Sexual Assault and Domestic Violence Treatment Centre)." Which for a lot of folks can be, at minimum 20 minutes, at maximum 45 . So, it can be a pretty long trek to physically get to the site. And then again not knowing the process looks like, because survivors don't and how could we expect them to know process? They think that they're facing another 8 hour wait in the emergency department before they see the nurse that might be able to help them. So, I think for a lot of folks, at that kind of first initial stage, they kind of say "Forget it. Do what you can for me here." Which is often things that - not that they're not important things like Plan B, STI testing, STI prophylaxis. Those kinds of things get dealt with and managed, but they lose the opportunity and the choice to have forensic involvement. For Northern participants, this reality accumulates with other barriers when other transportation factors such as larger catchment areas and weather-based road shutdowns become involved. Southern or Central Ontario based participants had varying travel time estimates for survivors to travel to their nearest Sexual Assault and Domestic Violence Treatment Centres, with the maximum being approximately one hour. For Northern Ontario participants, catchment areas for centres could be up to two hours in any direction, covering multiple community hospitals. In colder seasons, roads and highways can close within these areas, making it impossible for survivors to get to the nearest Sexual Assault and Domestic Violence Treatment Centre, or for the Sexual Assault Nurse Examiners to travel to them. 
When this barrier of transportation creates a time delay in attending hospitals, or causes a survivor to be completely unable to attend a Sexual Assault and Domestic Violence Treatment Centre, the barrier can snowball and cause additional problems for the survivor later on. Sexual Assault Evidence Kits are extremely thorough and are time-bound, so even in the time it takes for a survivor to travel from their local community hospital to a Sexual Assault and Domestic Violence Treatment Centre, the period of viable evidence collection is diminishing. This information is also based on the rare instance that a survivor attends a hospital immediately following the assault. Participant Jade explains the challenges that they have witnessed related to time constraints, explaining,

You can't get the evidence kit done if certain timelines aren't met or they've gone over. And it's different for pediatric versus adult cases, so there's also that piece. So, survivors are thinking about "What can I do? When can I do this?" But then there's also this timeline because of the medical piece.

Ash also explained how this timing compounds with the barrier of travel time in their community, saying,

Delay in assessment would be a barrier as well. And time, I think that the time involved as well with having to travel. Time is very important to survivors with examination, so to tack on an extra four hours to their already four hour exam, plus what they've experienced at their local hospital. Time is definitely a barrier too.

If there is a time delay in evidence collection or the evidence is collected by a medical professional who is untrained, further complications can occur within the legal and justice systems later. Criminal defense attorneys have a greater opportunity to argue that the evidence was collected improperly or by a professional without expertise and is therefore inadmissible. 
Alternatively, if the issue is time, they can argue that the evidence is less credible or inadmissible due to contamination risk. These scenarios reflect personal experiences shared by participants about the ways in which transportation as a broad issue creates a multitude of additional microbarriers to access. Participant Ash explained how having this reduced quality of training and care can not only impact the integrity of the evidence collection, but also impact the provider-patient relationship, saying,

If it was moving forward legally there would be some questioning of the evidence and how it was performed. If someone wasn't trained, then they wouldn't be able to speak to any sort of level of expertise. I think maybe the provider would be focused more taskoriented on reading through the instructions, so it may reduce confidence in the survivor. And so I think it would definitely pose a problem with the patient-nurse relationship. Next, the barrier of transportation intersects with a decreased quality of care overall when survivors cannot travel to access the follow up care necessary after medical and/or forensic health care. If a survivor is somehow able to arrange transportation to a distant hospital that has a Sexual Assault and Domestic Violence Treatment Centre to receive care, attendance for follow up care is lower than if the survivor was local to the hospital. This follow up, specialized and highly trained support for the physical, mental, and emotional wellbeing following an assault should always be an option for a survivor to choose whether or not to participate in. But for folks without access to transportation, the choice is not there. This was reflected by Quinn while explaining that the evidence collection is just one piece of care, and that the additional quality care for a survivor contributes to their well-being, but is not without barriers itself.

"Now the problem is, you've gone through this initial trauma, but how are we going to support you with follow up services and counselling? Especially if you don't have your 
own transportation. So, the kit is one part of it, but then the rest of everything that comes with that kit, other aspects of service.

A key factor that participants discussed in mitigating this potential harm is improved staff training in rural hospitals in order for them to provide follow up care, or to extend Sexual Assault and Domestic Violence Treatment Centres to have mobile nurses. These address the concerns vocalized regarding a lack of training in smaller, community hospitals that do not provide Sexual Assault Evidence Kits on how to best support survivors. Multiple participants told stories of survivors attending their local hospital, being triaged, waiting several hours to see a medical professional, and then being told that they do not provide sexual assault evidence kits, and that they must therefore travel a significant distance to the nearest Sexual Assault and Domestic Violence Treatment Centre. At that point, survivors may feel that it is not worth it to travel and choose to forgo the evidence collection. While it should always up to the survivor on whether or not to engage in the evidence collection process, again, the choice is removed in this circumstance. One participant ${ }^{1}$ explained a time in which they witnessed this barrier first hand. This situation was the catalyst for to advocate within their centre for the provision of mobile services, which they now provide.

A patient had to wait in the hospital waiting room for [several] hours who had been sexually assaulted, and then was told that they don't do that there, so she would have to go to (the nearest Sexual Assault and Domestic Violence Treatment Centre). And came here, and by that time it had been like [many] hours of having to sit in a waiting room with people that she knew. And revealed this problem - why did she have to wait? Why wasn't she brought back?

\footnotetext{
${ }^{1}$ The pseudonym of this participant has been left out to prevent the risk of revealing their personal identity.
} 
This lack of education and training in rural hospitals does not only impact the survivor's access to evidence collection, but provides a reduced level of sexual assault care in a number of other ways. Sexual Assault and Domestic Violence Treatment Centres have excellent standards of care and maintain significant policies to ensure high quality, trauma informed care that respects the dignity and confidentiality of the survivor. In medical services that do not have this training, education, and regulation, survivors may experience revictimization by having to repeatedly tell their story to multiple staff, have their care provided in an Emergency Department bay rather than a private, safe room, and may have their name and reason for being there posting on visible Emergency Department charts. Charlie explained how their centre navigates this in order to protect privacy,

One thing also that happens with our clients is that they may be feeling embarrassed or ashamed, and they don't want their name put on the tracking board in the emergency department, for example. So, when our clients come in they don't get put on that tracking board, they're put into a different code in our computer so that it's a more private situation.

Quinn also explained how their staff is intentional in documentation that is survivor-centred, but that without this training, charting can be biased against a survivor, It's even wording and coding, and how things are being reflected in charting during their care. So, I think for a lot of folks, they will avoid attending the emergency department at all. And that again removes their choice in the first place.

Additionally, participants in this study identified that some Emergency Department staff at smaller hospitals are unaware that there is a Sexual Assault and Domestic Violence Treatment Centre that they could be referring and supporting the survivor in getting to. 
Similar to experiencing reduced quality of sexual assault care within their local community hospitals, rural survivors also face barriers regarding confidentiality in a unique way. In communities with small populations, there is increased risks of the survivor being recognized by medical staff or service providers in their area. They may be friends, family members, neighbours, or even perpetrators. This alone can be a barrier to attending a hospital. Participants also expressed concerns around confidentiality with police and justice systems. Issues of perpetrators or their relatives and friends being involved heavily with police or justice systems lead to feeling powerless to interact with these systems safety, and gave their perpetrators protection from accountability. Participant Quinn explained how this could be a barrier even when connecting with services that may refer a survivor,

Trust is such a huge piece in fostering that disclosure. And if it's your family physician that you've had for years, it's your parents' physician - you'd be worried about that confidentiality piece. And again, I really think confidentiality is a huge barrier. When discussing these elements, one thing that each participant stated that they highly valued in making sexual assault care for rural survivors more accessible was creating partnerships with community agencies located in rural communities. Each of them recognized shelters, health care centres, sexual assault support services, LGBTQ2S+ services, and agencies that support BIPOC as being crucial in developing trusting relationships with survivors that empower them to feel safe attending a hospital and finding ways to facilitate and fund transportation. Every participant valued these relationships and spoke about their intentionality in forming relationships with these rural partners so that the providers knew that specialized sexual assault services existed, how to respond to a disclosure, and where to refer. By using these 
relationships, each participant and their agency had engaged in advocacy to reduce barriers for rural survivors.

\section{Intersections, Systems, and Safety}

The second major theme to emerge from the study was "Intersections, Systems, and Safety", which explores how survivor identities intersect with medical, legal, and policing systems following an assault, causing privilege and oppression to impact access, care, and justice.

As mentioned earlier, if a rural survivor does not have personal transportation, if they receive transportation outside of their county to a Sexual Assault and Domestic Violence Treatment Centre, it is almost always by police. This issue is fueled by funding, where smaller services to survivors or Sexual Assault and Domestic Violence Treatment Centre may not have the budgets or funding to cover transportation, but police services do. For many reasons, this is very problematic for survivor access and safety.

This reality creates unsafe situations in particular for Black survivors, Indigenous survivors, trans survivors, survivors with mental health, survivors with disabilities, survivors who engage in sex work, survivors experiencing homelessness, survivors who use substances, survivors who have previous involvement in the criminal justice system, or any other survivor that has experienced personal and/or collective violence by police and police systems historically and currently. Each participant outlined identified that certain rural marginalized groups face additional barriers to accessing Sexual Assault Evidence Kits because of the dependence on police to transport.

Connected with this, participants identified that having the sexual assault evidence kits embedded within medical and legal systems can be a barrier for rural survivors, particularly 
those are who are marginalized. The lack of trauma informed training and the presence of bureaucratic, oppressive systems in both the medical and legal systems can cause further revictimization due to the lack of sensitivity to the survivors' experiences. For communities that experience marginalization and oppression, the contact between police systems and medical systems can be even more traumatizing and insensitive, given the negative associations marginalized communities have with these systems. Jade explained this, saying, The legal and medical systems interface with each other very closely. So, that itself poses a barrier. Especially working with folks who historically or to present day have negative relations with systems that do marginalize by the mere fact of who the person is. So even if you take out the access to these Sexual Assault Evidence Kit, because it's embedded in a hospital. There are certain communities that do not interface with the hospital in general unless there is a crisis, or involuntarily.

Other participants gave personal stories of survivors being pressured by police and non-trauma informed medical staff to complete evidence kits, removing their opportunity for choice. One participant shared that they have witnessed survivors of drug facilitated sexual assaults be streamed by police into the Emergency Department under the label of "intoxication". These situations reflect the biases and discrimination that exist within medical and policing systems that deter survivors from accessing care following an assault. As Quinn explained, "When you're facing systemic oppression, racism, and gender bias, this is probably not the first time that you have been stigmatized against in a medical system and so why would that feel safe?".

Participants also shared stories about the barriers that exist when rural trans survivors have to depend on rural hospitals for care or police for transport. When social workers or nurses are trained to work in Sexual Assault and Domestic Violence Treatment Centres, they undergo 
detailed and intensive training on how to best support survivors of all identities and specifically how to talk about anatomy, gender, and sex in inclusive, respectful ways. In rural community hospitals that may not have this training, or when police interact with trans survivors, they may judge, invalidate, or revictimize the survivor. As Quinn explained,

Anyone who's presenting who is not cisgendered or is racialized, or if there's a language barrier, or as you said with intersectionality, if all of those are coming together, there's huge bias from the emergency departments, and that's not just here. That is across the province and across the country.

To address this issue, each participant described ways that they play active roles in forming and maintaining connections with rural community partners that support folks experiencing marginalization, in particular, racialized or LGBTQ2S+ folks. When these strong relationships are built between Sexual Assault and Domestic Violence Treatment Centres, service providers know where to refer rural survivors with diverse identities, and can confidently tell the survivors that they know the Sexual Assault and Domestic Violence Treatment Centre staff and can assure them they will be treated with quality care, dignity, and respect. As Quinn explained, this connection is key in helping survivors feel supported and confident in the quality of care that they will receive, saying,

We work very closely with our local sexual assault/rape crisis centre. If they have that connection, often times the sexual assault centre can see "Oh, Quinn is working tonight, they will take care of you. You will not face bias or stigma from their team. How can long can we stay with you in emerge until the team gets there, or can we book you an appointment? Or can you wait until tomorrow and then you can go in in a non-emergent pathway?" 
Additionally, depending on the relationship between the service provider and survivor, they may be able to accompany the survivor to the Sexual Assault and Domestic Violence Treatment Centre to provide advocacy and support during the care.

Together, the systemic racism, transphobia, and ableism embedded within medical and police systems maintain additional barriers for rural survivors accessing Sexual Assault Evidence Kits. Through relationship building with community partners and conducting trainings with police and smaller, rural hospitals, participants problem solved for systemic change to increase access and mitigate these barriers.

\section{Implications of COVID-19}

An unexpected theme when proposing this research was the impact that the COVID-19 pandemic has had on rural and non-rural survivors of sexual violence. When talking with participants, all of them spoke about how COVID-19 had influenced their experiences and the experiences of survivors. Predominantly, participants indicated that it compounds issues that already exist.

One of the most significant realizations that all participants noted was the increase in violence happening at this time. Physical distancing, mandatory quarantines, and urges to stay at home put survivors experiencing domestic or sexual violence by someone that they live with at increased risk. It also has them less visible in the community and isolated from work, neighbours, family, and friends, meaning that there are fewer supportive people in their lives to provide or connect them with services and safety. What concerned the participants most about the impact of COVID-19 measures on survivors, was that even though they knew that family violence had increased, there was still decreased or maintained numbers of survivors entering hospitals. This apprehension surrounding entering hospitals is believed to be because of a fear of 
contracting or spreading COVID-19. As noted by Jade, "Now [referring to COVID], it's even more inaccessible because people don't want to get sick. And so, that exasperates now not only the increase in incidents, but also the increase of inaccessibility."

For survivors who are able to access hospitals for care, a significant barrier identified by participants was that there are currently policies in place that do not allow visitors. This means that survivors accessing Sexual Assault Evidence Kits or post-assault care cannot have a support person there with them. This experience of Sexual Assault Evidence Kits process and/or postassault care is long, invasive, and exhausting, and having a support person present can help a survivor to feel more comfortable. One participant stated that through internal advocacy they are able to have one support person approved to stay with the survivor, but other participants have not received similar responses.

For survivors receiving follow up care amidst current COVID-19 restrictions, follow up care currently comes with its own complications. Hospital policies requiring all non-emergent care to be postponed through the pandemic, to minimize contraction risk and increase capacity to care for COVID patients, created a new barrier for survivors. Under current restrictions, follow up care is provided over the phone by nurses and social workers. While this may be okay for survivors who prefer it to attending the hospital follow up appointments, it compounds the barriers for survivors experiencing violence from someone within their home. If a survivor lives with their perpetrator, safely communicating with staff on the phone may not be an option. Participants explained that they develop safety plans with survivors to reduce this risk, but the barrier remains. For survivors who do not live with their perpetrators, phone contact can still be less comfortable than face to face and less private depending on their living situation. Having other people in the home or not having a private space to talk may contribute to further 
discomfort. As described by participant Jade, “Clinical work has shifted very much so, in that it's not accessible for everyone. Because they can't come out to us or be in a space that's private."

Another barrier listed by two participants is that many community partners and health care professionals, which had already been identified as positive elements in supporting survivors and connecting them to Sexual Assault and Domestic Violence Treatment Centres, are not operating at their full capacity during COVID-19. All agencies and family physicians that were able to provide support remotely through the pandemic were mandated to do so remotely by the Government of Ontario, resulting in closures of agencies that supported survivors in many ways.

Quinn explained the unique phenomenon and its wider impact on health care access, saying, "A lot of that communication is through family physicians, public health, which again is a unique challenge in this pandemic because follow up services aren't existing in the community right now." Some agencies have returned to service with adaptations in place to support physical distancing and others have remained open through the pandemic, but modifications still exist that alter the ability to connect with clients in the way that they previously could. By having decreased, altered, or limited services provided by rural community agencies due to COVID-19, rural survivors experience increased barriers and obstacles in accessing support, transportation, and referrals to sexual assault services.

A key point that participants spoke to was that the COVID-19 pandemic compounded and highlighted issues that existed long before the pandemic. Barriers to service and rises in family violence were given political and media attention in a way that they had not received before. It was having families mandated to stay home that sparked conversations about how home is not safe for many survivors and their children, and how being visible and involved in the 
community helps to maintain safety. As mentioned by one participant, the tragic mass shooting in Nova Scotia, fueled by misogyny and intimate partner violence, brought national attention to the risks and severity of gender-based violence. Again, advocating for resources, policies and change are what service providers within the field of sexual and domestic violence have been doing throughout history, but it took the combined tragedy of the pandemic and the mass shooting for this crisis to receive the attention necessary. One participant, Quinn, expressed frustration at the current circumstances in this passionate quote,

It somehow took a pandemic for there to be money, and it took a pandemic for there to be funding, and it took a pandemic for there to be a highlight on the fact that these domestic and sexual violence calls are increasing and yet we can't provide access to service because of numerous barriers that already existed before, and are now compounded. And it's great and it's wonderful and I'm thankful that if there's one good thing that's come out of this pandemic it's the highlight on the work that needs to be done in this area. But it's also frustrating to be like "I've been working towards this for years!" This quote reflects the drive for change that exists within the survivor and service provider community to give this issue the attention, funding, and political response that it requires. The new barriers related to the COVID-19 pandemic and the complications that it creates for survivors accessing Sexual Assault Evidence Kits have, if nothing else, brought this issue more media and political recognition. It is the hope among participants, as well as myself, that this energy and focus can be sustained after the pandemic, to help provide funding and long-term, strategic change and solutions. 


\section{Resilience, Resistance, and Transformation}

The fourth and final theme to emerge from this research is the dedication that each participant gave to the role as a service provider to survivors of sexual and domestic violence. Each and every participant was able to provide critical, detailed, and innovative solutions that they advocated for in a variety of ways. Some had administered formal needs assessments to the survivors they have supported, while others had taken less formal approaches. But all of them were diligent about understanding the specific barriers that survivors had to accessing their Centre and addressing these issues in tangible ways. As one participant, Jade, explained, the service providers show their commitment to supporting survivors by striving to unite the survivor community for change.

We show resistance through the advocacy piece of wanting to do more and work with each other. I think survivors as well are part of people who provide the support too, and also are in the community as well. I think that's part of our work and what we do. We not only do the work, but we do the pieces around pushing back when something isn't working. And how do we actually rely on each other to do this work, rather than just do it ourselves?

When considering solutions to the inaccessibility of Sexual Assault Evidence Kits, the most common suggestion was the creation of mobile units where an on-call Sexual Assault Nurse Examiner would attend a rural hospital within their catchment area to complete a Sexual Assault Evidence Kit. Some participants in this research came from Sexual Assault and Domestic Violence Treatment Centres that currently provide mobile services to rural survivors, while others came from locations that did not. One participant ${ }^{2}$, from a Sexual Assault and

\footnotetext{
${ }^{2}$ The pseudonym of this participant has been left out to prevent the risk of revealing their personal identity.
} 
Domestic Violence Treatment Centre that is hoping to go mobile explained how a lack of funding results in this barrier, saying,

I could launch a mobile team tomorrow and I've got nurses that could support that. It wouldn't take much to get this up and running. But, we have to pay the staff, we have to be able to support the transport, we have to be able to set up a facility.

This quote reflects the passion that Sexual Assault and Domestic Violence Treatment Centre Staff have to support survivors, but that they themselves face barriers in expanding access.

For participants whose centres did not provide mobile services, the main reason that they continue to advocate for them is a belief that survivors deserve quality care in their own communities to reduce the need to travel. Charlie explained, in an empathetic way, why they believed this must exist, saying,

The worst thing I can think of is being sexually assaulted and then once you get to your local hospital, being told 'I'm sorry, we don't do that here. You'll have to get back in your car and travel half an hour to an hour away.

These participants had identified that leaving their home communities was a barrier for survivors and wanted to collectively reduce that barrier. However, this is not without complications to implement.

Notably, funding was listed as the top obstacle in expanding the geographic capabilities of Sexual Assault Nurse Examiners. Stocking the Sexual Assault Evidence Kits, staffing nurses to cover multiple hospitals, and covering mileage reflect some of the financial expenses involved in expanding this access. One participant explained how if they were to provide mobile Sexual Assault Evidence Kits within their catchment area hospitals, they insisted it be done with the 
level of care, dignity, quality, and training that the survivor would receive in an urban hospital with a Sexual Assault and Domestic Violence Treatment Centre. Quinn explained,

I would not want the level of care to differ because we're in a smaller rural site. I don't want to be in an emergency department bay where we have that magical privacy curtain that all of the sudden makes things soundproof. I don't want that, I don't think survivors deserve that. I think that they deserve a certain level of care wherever they are, and that we should be able to facilitate that. One of the easiest ways to do that would be to appropriately fund services.

This statement speaks to the necessity that if Sexual Assault Nurse Examiners are to be attending rural hospitals to provide post-assault care, the hospital must be physically prepared and trained for their arrival. This means a private, safe space, made to be as comfortable as possible with care provided by a competent, empathetic nurse. Providing care in a busy, crowded Emergency Department room with only curtains for privacy and several medical professionals popping in and out does not provide the quality care that the survivor deserves and requires following such a traumatic event.

In contrast, one participant from a Northern community stated that mobile units did not fit the way that they provide service, and that the best method for them to support survivors in their communities was to find ways to transport them to the Sexual Assault and Domestic Violence Treatment Centre. When the catchment area of a Sexual Assault and Domestic Violence Treatment Centre covers multiple hospitals that could be hours in any direction, having a Sexual Assault Nurse Examiner travel to a community hospital could leave the other hospitals without available sexual assault care for hours at a time. This is due to the difficulty of having high enough of numbers of trained staff available in Northern Sexual Assault and Domestic 
Violence Treatment Centres. If there are only a few Sexual Assault Nurse Examiners covering a large geographic area with many rural hospitals and only one is paid to be on call at a time, when that nurse attends one smaller hospital, the rest are without care for the entirety of the survivor's care, plus travel time. For them, this meant a solution where the transportation of a survivor is compensated and provided by non-police related services. When asked about how they felt this barrier could be addressed, Ash explained, I would definitely say provincial support for alternative transportation. So, more funding to Victim's Services, for volunteers that can be taken out of their region. Because safety while travelling is always a consideration as well.

This situation represents the complexity of access and the need for individual solutions based on specific geographic and population needs.

Another participant ${ }^{3}$ was able to advocate for the provision of mobile units from their Centre, and now provides them to rural hospitals within their catchment area. This team had navigated technical, training, and financial obstacles in order to implement this service, but identified a greater, systemic support as being at the basis of why they received the approval that they required.

All participants connected that the core of why rural hospitals cannot provide Sexual Assault Evidence Kits is rooted in survivor quality of care. Sexual Assault Nurse Examiners go through extensive training to operate in their role, as well as yearly refresher courses and constant updates and training through the Ontario Network of Sexual Assault and Domestic Violence Treatment Centres. By conducting Sexual Assault Evidence Kits in urban hospitals or hospitals that serve large catchment areas, Sexual Assault Nurse Examiners see a high enough number of patients to remain competent in their work. This means that if they were to testify in

\footnotetext{
${ }^{3}$ Quote and pseudonym have been left out to prevent sharing potentially identifying information.
} 
court, they can speak to a level of expertise and quality. Overall, this supports the best interest and well-being of the survivor. If a Sexual Assault Nurse Examiner was to operate out of a smaller hospital that is not designated as a Sexual Assault and Domestic Violence Treatment Centre, they would not see survivors on a consistent enough basis to maintain their expertise in evidence collection. This supports the solution of mobile units, so that survivors can receive care from Sexual Assault Nurse Examiners who is competent in their care, within their home community.

To facilitate survivors accessing Sexual Assault Nurse Examiners located within Sexual Assault and Domestic Violence Treatment Centres, two of the participants had systems in place where they could provide taxi vouchers to transport survivors from their local hospital, and home again following care. Additionally, if the case is non-emergent, all participants were able to fund travel through Victim Services. Accessing the Victim Service program is not without its own barriers, however. Participants explained that sometimes survivors understandably do not know that Victim Services is separate from the police, due to their close relationship. Quinn explained, "Folks think that victim's services, because they're housed out of police and work so closely with police, that becoming involved with victim's services means they're now involved in a police process." If the survivor does not want police involvement, they may choose to forgo Victim Services involvement as well. One thing was clear from all participants was a dedication to getting the survivor where they needed to be. Quinn participant shared this quote, which reflects the commitment that all participants had to getting survivors the care that they needed, where they needed it. 
We'll try to facilitate care as much as we can, and we'll troubleshoot with clients. If you somehow made it to us - How can we get you home? How can we facilitate that follow up care? All of those pieces.

The passion and dedication to removing barriers for survivors shown here does not only apply to transportation, but participants also explained other ways in which they have resisted and broken down these barriers. Another major way that every participant fought to increase their presence and accessibility was forming intentional connections with rural service providers, police, and hospitals. Each participant identified boards that they sit on, trainings that they lead, and relationships that they built, in order to ensure that service providers know how to create safe spaces for disclosures, how to support survivors, and where to refer them for care. Building this connection and awareness also creates accountability for other agencies and police departments to be supporting survivors as best they can. Quinn explained a message that give to community partners, hospital staff, or police interacting with a survivor and facilitating a referral, "I don't need you to be an expert in sexual violence, I need you to be an empathetic human being who can foster a disclosure and make a survivor feel safe and supported, reassured, and empowered to have choice." Ash had similar reflections, and when asked what the most significant action they had taken to facilitate access to Sexual Assault Evidence Kits in their community was, responded, "I would say by nurturing those relationships with our community partners and with our district partners, definitely. And as I said, we make a priority to nurture those relationships.” Ultimately, relationships are at the core of providing quality care to survivors, and in this case, the participants extended these relationships to provide a greater circle of care.

Participants also discussed creative solutions that they have made to increase their presence in the community and make Sexual Assault and Domestic Violence Treatment Centres 
more visible for folks who may need them, especially during the COVID-19 pandemic. The Ontario Network of Sexual Assault and Domestic Violence Treatment Centres has created a navigation telephone line that survivors can now call to speak to a nurse and understand how to connect with a Centre and receive support. The nurse is also able to answer any specific questions that they may have surrounding the impact of COVID-19 on their care, and to validate the personal protective equipment protocols that are in place to keep them safe. Some participants had even created their own similar materials on social media curated to survivors within their community, for a more personal and consistent approach.

Together, all of these creative solutions reflect the drive and passion within the service provider community to expand and facilitate access to Sexual Assault Evidence Kits. By funding and advocating for transportation, building relationships with agencies that are the first contact with survivors, and creating navigation programming for survivors, the sexual assault service provider community is resisting the barriers placed upon them and constructing an accessible path to services. The service provider and survivor community has shown resilience through these barriers throughout history, and as one participant stately so strongly that it became the title of this paper, they are still fighting.

“The fact that we're still here, we're still fighting, we're still trying to seek access, means that we haven't given up." - Quinn

\section{Conclusion}

In closing, four main themes arrived from the interviews, exploring the barriers that exist for rural survivors accessing Sexual Assault Evidence Kits. The first theme, "Rural Realities", unpacked how factors such as transportation, confidentiality, and a lack of training in smaller hospitals and police services can create barriers to survivors attending Sexual Assault and 
Domestic Violence Treatment Centres. The second theme, "Intersections, Systems, \& Safety", discussed how intersections of identities, racism, and transphobia can bar marginalized survivors from accessing the care that they require through the medical system, and safely interacting with police. The third theme, "Implications of COVID-19", explained how political and medical systemic changes related to the current pandemic created increased family violence and a fear of attending hospitals. Lastly, the fourth theme explored how service providers to survivors have continued to resist these barriers in order to create sustainable solutions to increase access for survivors, build relationships with community partners, and support survivor wellbeing. 


\section{Chapter 6: Discussion}

\section{Introduction}

This chapter further discuses the concepts and themes that arrived through the interviews through the lens of the theoretical framework, Intersectional Feminism, and in relation to the material reviewed in the "Literature Review" chapter. As stated in the "Theoretical Framework" chapter, this method of inquiry was selected due to its relevance to gender-based violence, as it approaches inquiry by evaluating elements of power, privilege, empowerment, and emancipation (Beckman, 2014). Employing this, the themes that emerged, Rural Realities; Intersections, Systems, and Safety; Implications of COVID-19; and Resilience, Resistance, and Transformation, are analyzed using this lens. Additionally, the implications and limitations of this research are discussed.

\section{Rural Realities}

When formulating ideas for what this research sought to understand, something that linked strongly to the research question was the attempt to learn if rural location could also be considered a social location. This meant understanding the ways in which aspects of living in a rural location create distinct barriers for survivors, and how those supporting them most closely believed these barriers could be addressed. For example, when considering differences in accessibility in Northern versus Southern Ontario, travel time and road closures can make accessing a Sexual Assault and Domestic Violence Treatment Centre impossible.

When searching for participants, I did not know where interested participants would be located, and while I hoped that it would be widespread across the province, there was no guarantee of this. During the literature review, there was no published information regarding the differences between Northern and Southern accessibility, so it was interesting to hear from 
participants from across the province about the observed differences between the two.

Personally, this highlighted that every community is unique in its needs and that solutions require a personalized and individual approach.

Next, the most significant barrier listed regarding rurality was the dependency on police to transport survivors to Sexual Assault and Domestic Violence Treatment Centres, as this was stated by every participant. When applying a gender-based analysis on how patriarchy and oppression impact survivor experiences, having police be the first contact understandably creates many barriers. As a profession, policing is rooted in oppression, violence, and surveillance, and overwhelmingly negatively impacts particularly vulnerable survivors, such as survivors who are trans, racialized, or have mental health (Campbell \& Fehler-Cabral, 2018; Moylan et al., 2017; Shaw et al., 2016). Additionally, policing is highly male dominated profession, with women accounting for only $22 \%$ of police officers nationally (Statistics Canada, 2019). While a social worker, registered nurse, or staff member at a Sexual Assault and Domestic Violence Treatment Centre is mandated to provide trauma informed medical and forensic care that is survivor centred, police officers have very different mandates (Du Mont et al., 2018, 2019; Du Mont \& Parnis, 2003; Stermac et al., 2005). In situations of sexual and domestic violence, their obligation is to investigate and lay charges if they deem it necessary. This difference within itself manifests into entirely contrasting ways of interacting with survivors. While some police officers may be trauma informed or adopt that lens, many do not (Campbell \& Fehler-Cabral, 2018). When survivors are forced to rely on police officers to transport them, it creates an inequity in who can access Sexual Assault Evidence Kits, removes the choice in whether or not to involve police, and provides an opportunity for revictimization (Campbell \& Fehler-Cabral, 2018; Greeson \& Campbell, 2011). 


\section{Intersections, Systems, and Safety}

This second theme is where the intersectional aspect of Intersectional Feminist Inquiry was most relevant. At the basis of this theme was participants' observations about additional barriers that exist for survivors due to social location and diverse identities. Predominantly, these were about survivors not feeling safe to interact with medical and police systems due to ongoing and historic violence against their communities. When compounded with factors related to rural location, such as a dependency on police to provide transportation or having higher travel times impact the integrity of the evidence, these survivors face a multitude of cooccurring barriers. This compilation of factors preventing access for survivors may result in a reluctance to engage with police or medical systems and a justified lack of trust in those they are forced to interact with. Participant Charlie explained how trust is crucial in supporting survivors and why certain folks may not trust medical professionals or police. Saying, "Especially with the vulnerable people as well. Especially those who have been judged by medical professionals or judged by police, they may not have that trust." Participant Jade echoed this and noted how this is especially true for folks who are racialized,

If you're looking at intersectionality where race is central, there's already a barrier there in regards to Black, Indigenous and racialized identified folks. And so, even talking about incidents of IPV [Intimate Partner Violence] and sexual assault and or sexual assault in the home, can be difficult.

When drawing connections between barriers and social location, it is vital to understand that when police and medical system interaction are necessary to access an evidence kit, there will be survivors who cannot safely access one. These observations are supported by the literature, which talks about ways in which privilege and oppression impact survivor safety for trans and 
racialized communities (Du Mont et al., 2019; Greeson \& Campbell, 2011; Stermac et al., 2005). Additionally, these authors talk about how trained Sexual Assault Nurse Examiners can be most supportive of trans and racialized folks and reduce revictimization.

\section{Implications of COVID-19}

When a global pandemic hit amidst my research project, it dramatically impacted survivors and service providers in a number of ways (Bradbury-Jones \& Isham, 2020; John et al., 2020). Because of the unique time in history, it felt imperative to give these observations their own, dedicated theme with the recognition of how rural barriers to Sexual Assault Evidence Kits become compounded during a pandemic. Most notably mentioned that many survivors do not feel safe entering hospitals due to the risk of contracting or spreading COVID-19, despite increased levels of violence during self-isolation and quarantine (Bradbury-Jones \& Isham, 2020; John et al., 2020). Additionally, the added complication that they often cannot have a support person with them during the long, extensive, and invasive forensic and medical procedure was noted. This unique and unexpected theme increased the scope of this research by identifying how the at-home restrictions and stress of COVID-19 has increased family violence while reducing contact with service providers and the benefit of receiving those services, which has significant implications for future care planning with pandemics in mind. There has also been a recent media highlight surrounding domestic and sexual violence during the pandemic, and hopefully this focus can be maintained to create meaningful solutions for survivors and facilitate ongoing access to support services. Jade proposed that this media highlight and current focus on sexual and domestic violence in the time of pandemics be used to facilitate tangible solutions to these barriers, saying, 
This has been a problem before this - pre pandemic. There's been barriers before, but it's being looked at more closely right now, because it's in the community at the forefront. So, I think that's why people are like, 'Maybe we need to take a look at this.' And if you look at, the organizations and academics who engage in this work have lots of resources made and workshops, and things on what to do. Those materials and resources, we already knew about them, we already know. But it's more around, what do we actually do to make responses sustainable, meaningful, and reduce further trauma and violence by the systems itself? But also considering that we never thought about pandemics, or mistreatment of this kind.

This critical quote highlights that there is already strong evidence that supports the existence of barriers to sexual assault and domestic violence care. But that now, when the attention has been focused on these barriers compounding with a global pandemic, that action is taken to intentionally address these barriers and increase preparedness in the event of a future crisis.

\section{Resilience, Resistance, and Transformation}

The fourth and final theme to arise from the research was how rural survivors, service providers, and their organizations engage in ongoing resistance regarding the inaccessibility of Sexual Assault Evidence Kits. This was done from a motivation for transformative change within the system, and revealed creative solutions that participants implemented or hoped to implement. The most common solution was the transition to mobile units, which is supported by literature (Du Mont et al., 2019; Du Mont \& Parnis, 2003; Sievers et al., 2003; Stermac et al., 2005) This is because of the higher rates of accuracy when Sexual Assault Evidence Kits are completed by Sexual Assault Nurse Examiners. By creating mobile units, Sexual Assault Nurse Examiners are able to conduct evidence collection and post-assault care within the survivor's home community 
and local hospital - thus reducing the need to travel while also providing competent, quality care. Survivors deserve this quality care provided by a trained professional who maintains feminist principles of respect, dignity, and choice.

All of the participants were formally trained in trauma informed care with intersectional feminist principles and aimed to reduce barriers for survivors that are particularly marginalized by police and medical systems. Many of the participants took it upon themselves to personally educate other service providers about barriers, strongly reflecting feminist principles of emancipation and empowerment (Falcón, 2016).

\section{Research Question}

When reflecting back on the research question, which was "What are the experiences of rural survivors accessing Sexual Assault Evidence Kits?” it appears as though the question was answered in a broad, but thorough, way. Participants reflected that the experiences of rural survivors are significantly impacted by a number of factors related to identity, access, privilege, and oppression. When reflecting on this, I wondered if the question was too one-dimensional to begin with. The question almost assumed privilege in the sense that it viewed rurality as the only factor that inhibited access, when there is strong evidence that there are many other barriers to access. However, this question did provide me with the opportunity to learn about the ways in which rural location compounds multiple barriers for survivors, and how responses must consider all of these factors and identities.

Despite this mishap, the participants answered the research question well and spoke to situations where rurality was one of the barriers, but also discussed how it compounded with other realities to create additional barriers to access. These reflective, well thought out responses helped to give depth to the research and broaden the scope of experiences explored. 


\section{Ethics}

Prior to applying for Ethics approval, one of the biggest aspects that I had to consider was whether to interview survivors or service providers. To prevent revictimization and a re-telling of traumatic experiences, I chose to interview service providers. Reflecting upon this, I believe that this was the right decision as it resulted in answers that spoke to a broader range of experiences and scenarios, as well as to systemic inequity and barriers. By interviewing service providers, the answers also explored potential solutions that were specific to the locations of the participants, and gave clear, tangible ways to respond to this inaccessibility. From an ethical perspective, this decision also avoided the risk of re-traumatizing and likely resulted in a higher number of participants.

When applying for Research Ethics Board approval, I was fortunate to experience very few complications. Many of my adjustments were related to security surrounding the audio files of the interviews and their subsequent transcription files once the interviews switched to digital methods due to COVID-19. Each of these suggestions were easy to implement and straightforward in their execution.

\section{Strengths and Limitations}

Overall, this research had many strengths, but was not without limitations. In terms of strengths, one strength was having four, in depth, one-hour long interviews from participants from different locations that were widespread across Ontario; there were varying perspectives that spoke to an issue that spans geography (Barusch et al., 2011; Sundler et al., 2019). The indepth interviews and the robust responses from participants produced not only a large amount of data to analyze, but gave a wide variety of answers from service providers from differing professional roles (Barusch et al., 2011; Beckman, 2014; Nowell et al., 2017; Sundler et al., 
2019). Another strength of this research is that it explored a significant gap within research around access to Sexual Assault Evidence Kits, by focusing specifically on rural location. Additionally, the final question in the interview asked the participants if there was anything else that they would like to add or felt as though was missed in the interview questions, creating space for anything that may be relevant to the research but not probed for (Beckman, 2014).

In regards to limitations, the research could have had more diverse perspectives or additional interviews from service providers from differing areas in order to strengthen the themes (Beckman, 2014; Campbell \& Wasco, 2000). The demographic identities of the participants were intentionally left out to protect confidentiality and potential identification, but overall, the research could have benefitted from a broader range of voices and backgrounds (Beckman, 2014; Campbell \& Wasco, 2000). This also translates to the diversity of which survivors can safely interact with medical systems in order to receive services from participants. As discussed earlier, there are certain populations, such as racialized, LGBTQ2S+, or Indigenous folks, that cannot safely interact with medical and police systems, so their attendance in hospitals is decreased. Because of this, participants cannot speak to their specific barriers or experiences.

Lastly, because the research is qualitative and not quantitative, it speaks to an issue identified by participants and a need for change, but cannot prove that rural location is a barrier to accessing Sexual Assault Evidence Kits.

\section{Implications}

An important implication of this research is its ability to contribute to the canon of knowledge that can inform changes that can be made to increase access to Sexual Assault Evidence Kits for rural survivors. Participants gave many answers about possible solutions to this barrier, specifically funding, facilitating non-police related transportation, and providing 
mobile units to smaller community hospitals. However, these were not considered to be universal solutions, and spoke to the need for community-specific solutions.

As identified by participants, the best way to apply these results is to appropriately fund research and programming that can facilitate access to Sexual Assault Evidence Kits and follow up care. With an increased understanding of this issue and potential solutions, agencies and decision makers could adopt some of these suggestions in ways that reduce barriers for rural survivors. Additionally, training for all service providers who may be first contact with survivors, such as police or community hospitals, may be done to better address this issue. Ultimately, the participants provided practical ideas to reduce this barrier that translate well as into implications and solutions. These suggestions echoed the recommendations of the literature, which discuss the ways in which funding helps support the provision of mobile care and training for emergency departments, Sexual Assault Nurse Examiners, and police to respond appropriately to survivors seeking care (Annan, 2011; Du Mont et al., 2018, 2019; Du Mont \& Parnis, 2003; Johnson \& Hiller, 2019; Stermac et al., 2005).

This MRP also has implications for additional research with the field of gender-based violence for rural survivors. Further exploration of the differences in access between rural Northern Ontario and Southern Ontario communities would be of benefit, as well as understanding future ways to create sustainable transportation methods and/or train smaller hospitals. These suggestions are intended to complement other areas of sexual assault care research recommendations, many of which are around training responders, understanding barriers, increasing access to care, and advocacy within the legal, justice, and medical systems (Annan, 2011, 2014; Du Mont et al., 2018, 2018, 2019; Du Mont \& Parnis, 2003; Greeson \& Campbell, 2011; Stermac et al., 2005). Finally, research into the many ways that COVID-19 is 
compounding this issue and impacting survivors of domestic and sexual violence globally is imperative at this time in order to have pre-existing systems in place to support survivors in the event of future global crises (Bradbury-Jones \& Isham, 2020; John et al., 2020).

\section{Conclusion}

In conclusion, the resulting themes of this research have strong relationships with feminist inquiry, and the participants embodied feminist approaches within their work by recognizing power imbalances, the gendered nature of violence, and providing trauma informed care with an emphasis on choice (Campbell et al., 2009; Du Mont \& Parnis, 2003; Falcón, 2016). Achieving ethics approval to complete this research was not complicated, however changes were made due to COVID-19 to support participant wellbeing. Strengths of this research include the amount of data provided by participants and their widespread locations, and limitations include the limited diversity of the participants and the survivors that they support. The results of these interviews have practical implications for change within the field of social work and policy. By properly allocating funds to transport survivors and train community partners that they may come into contact with first, access to Sexual Assault Evidence Kits can be increased. 


\section{Chapter 7: Conclusion}

I employed an intersectional feminist approach to understanding the experiences of rural survivors accessing Sexual Assault Evidence Kits and the barriers that they encounter. To do this, I completed four semi-structured interviews with service providers from across Ontario. Three of the participants were registered nurses, and the other was a social worker. Participants were asked questions about their experiences, the barriers that they identified for survivors, and potential solutions that they saw reducing this barrier. Participants gave thoughtful, critical answers and gave examples of ideas that they had personally implemented to support survivors in attaining transportation and access.

The interviews were transcribed and analyzed for emerging themes. This was done as a narrative thematic analysis, where different phrases and words were highlighted to identify commonalities between interviews. After this step, the highlighted points were observed to identify four major themes - Rural Realities; Intersections, Systems, and Safety; Implications of COVID-19; and Resilience, Resistance, and Transformation.

Rural Realities explored how rural location is a unique factor in accessing Sexual Assault Evidence Kits and how subjectivity rurality relates to barriers. Barriers such as confidentiality with local hospitals and services, reliance on police to transport, and decreased quality of care when attending a local hospital are explored.

Next, Intersections, Systems, \& Safety, discussed how other identities that survivors hold can compound with rurality to create additional barriers to access. Participants discussed how the police and medical systems can be unsafe for survivors who identify as trans, racialized, or having mental health experience discrimination in these systems, creating bars from access. 
The third theme to emerge was Implications of COVID-19, which was an unexpected theme when originally proposing this research. This theme drew from participant responses about how the current COVID-19 pandemic has caused an increase in violence for survivors living with their abusers, with decreased attendance to hospitals due to a fear of contracting or spreading the virus. Participants spoke of how they have tried to reassure survivors that there are proper procedures in place to keep them safe, such as advocating for them to have a support person present despite "No visitors" policies and educating them about PPE protocols. Their Provincial Network has also created a navigation line that validates survivors' fears and educates them about practices in place to ensure their safety at a hospital.

Lastly, the final theme was Resilience, Resistance, and Transformation, which reviews the ways in which service providers and survivors have remained resilient in this inaccessibility, and problem solved to facilitate access and reduce barriers. Additionally, their suggestions for sustainable solutions are explored. Notably, funding transportation that is non-police related and mobile units, and training for rural social and health service providers are proposed.

These four themes were then analyzed from an intersectional feminist perspective in the discussion section. Strengths, limitations, and ethical concerns are also explored, as well as suggestions for further research to provide more investigation into this issue.

Ultimately, it is vitally important that survivors have the choice in whether or not to attend a Sexual Assault and Domestic Violence Treatment Centre following an assault, and to have a choice to receive medical care and evidence collection. The purpose of this research is to understand how rurality is a barrier to this choice, and to provide potential solutions to the issue. With further research, funding, and implementation of these ideas, it is my hope that survivors across Ontario may be empowered with options, choice, and quality care when they need it most. 


\section{APPENDIX A}

\section{Ryerson}

University

\section{Interview Guide}

1. Can you please describe to me your background and role in supporting rural survivors of sexual violence?

2. What has your experience been with supporting rural survivors in accessing Sexual Assault Evidence Kits?

3. What barriers have you witnessed for rural survivors accessing Sexual Assault Evidence Kits?

a. How have you navigated these barriers, both as an individual service provider and as an agency?

4. How is rural location a unique factor for survivors accessing SAEKs?

5. In your experience, how does intersectionality, privilege, and oppression, play a role in the accessibility of SAEKs for rural survivors?

6. Have you engaged in any systemic advocacy to increase access to SAEKs in your community?

a. If yes, what forms of advocacy have you engaged in?

b. If yes, what responses have you received from medical system?

c. What response have you received from the political system?"

7. Based on your experiences and the gaps you have identified, what suggestions do you have to fill these service holes and expand access to SAEKS?

a. Have you or your agency identified any creative solutions to this problem?

8. Can you tell me about how you have seen the survivor community, including service providers and survivors, show resistance to this inaccessibility?

9. Is there anything else you would like to share? 


\section{References}

1in6. (2020). The 1 in 6 statistic - sexual abuse and assault of boys and men. 1in6. https://1in6.org/get-information/the-1-in-6-statistic/

Annan, S. (2011). "It's not just a job. this is where we live. this is our backyard": The experiences of expert legal and advocate providers with sexually assaulted women in rural areas. Journal of the American Psychiatric Nurses Association, 17(2), 139-147. https://doi.org/10.1177/1078390311401024

Annan, S. (2014, October 28). 'We desperately need some help here'-The experience of legal experts with sexual assault and evidence collection in rural communities. https://doi.org/10.22605/RRH2659

Barter, S. (1997). Social work students with personal experience of sexual abuse: Implications for diploma in social work programme providers. Social Work Education, 16(2), 113132. https://doi.org/10.1080/02615479711220181

Barusch, A., Gringeri, C., \& George, M. (2011). Rigor in qualitative social work research: A review of strategies used in published articles. Social Work Research, 35(1), 11-19.

Beckman, L. J. (2014). Training in feminist research methodology: Doing research on the margins. Women \& Therapy, 37(1-2), 164-177. https://doi.org/10.1080/02703149.2014.850347

Biernacki, P., \& Waldorf, D. (1981). Snowball sampling: Problems and techniques of chain referral sampling. Sociological Methods \& Research, 10(2), 141-163. https://doi.org/10.1177/004912418101000205 
Bradbury-Jones, C., \& Isham, L. (2020). The pandemic paradox: The consequences of COVID19 on domestic violence. Journal of Clinical Nursing, 29(13-14), 2047-2049. https://doi.org/10.1111/jocn.15296

Campbell, R., Adams, A. E., Wasco, S. M., Ahrens, C. E., \& Sefl, T. (2009). Training interviewers for research on sexual violence: A qualitative study of rape survivors' recommendations for interview practice. Violence Against Women, 15(5), 595-617. https://doi.org/10.1177/1077801208331248

Campbell, R., \& Fehler-Cabral, G. (2018). Why police “Couldn’t or Wouldn't” submit Sexual Assault Kits for forensic DNA testing: A Focal Concerns Theory Analysis of untested rape kits. Law \& Society Review, 52(1), 73-105. https://doi.org/10.1111/lasr.12310

Campbell, R., \& Wasco, S. M. (2000). Feminist approaches to social science: Epistemological and methodological tenets. American Journal of Community Psychology, 28(6), 773-791. https://doi.org/10.1023/A:1005159716099

Canadian Women's Foundation. (2020). The facts | Sexual assault and harassment in Canada. Canadian Women's Foundation. https://canadianwomen.org/the-facts/sexual-assaultharassment/

Carter, S. M., \& Little, M. (2007). Justifying knowledge, justifying method, taking action: Epistemologies, methodologies, and methods in qualitative research. Qualitative Health Research, 17(10), 1316-1328. https://doi.org/10.1177/1049732307306927

Denzin, N. K. (2017). Critical qualitative inquiry. Qualitative Inquiry, 23(1), 8-16. https://doi.org/10.1177/1077800416681864 
Du Mont, J., Kosa, S. D., Solomon, S., \& Macdonald, S. (2019). Assessment of nurses' competence to care for sexually assaulted trans persons: A survey of Ontario's Sexual Assault/Domestic Violence Treatment Centres. BMJ Open, 9(5), e023880. https://doi.org/10.1136/bmjopen-2018-023880

Du Mont, J., \& Parnis, D. (2003). Forensic nursing in the context of sexual assault: Comparing the opinions and practices of nurse examiners and nurses. Applied Nursing Research, 16(3), 173-183. https://doi.org/10.1016/S0897-1897(03)00044-2

Du Mont, J., Solomon, S., Kosa, S. D., \& Macdonald, S. (2018). Development and evaluation of sexual assault training for emergency department staff in Ontario, Canada. Nurse Education Today, 70, 124-129. https://doi.org/10.1016/j.nedt.2018.08.025

Du Mont, J., White, D., \& McGregor, M. J. (2009). Investigating the medical forensic examination from the perspectives of sexually assaulted women. Social Science \& Medicine, 68(4), 774-780. https://doi.org/10.1016/j.socscimed.2008.11.010

Falcón, S. M. (2016). Transnational Feminism as a paradigm for decolonizing the practice of research: Identifying feminist principles and methodology criteria for US-based scholars. Frontiers: A Journal of Women Studies, 37(1), 174-194.

Gore, M. T., \& Black, P. J. (2009). Bachelor of Social Work (BSW) students' prior sexual abuse victimization. Journal of Teaching in Social Work, 29(4), 449-460. https://doi.org/10.1080/08841230903249786

Government of Canada, Department of Justice. (2017, October 31). Victimization of Indigenous women and girls—Just Facts. https://www.justice.gc.ca/eng/rp-pr/jr/jfpf/2017/july05.html 
Government of Canada, Statistics Canada (2006). Measuring violence Against women: Statistical trends 2006: Prevalence and severity of violence against women. https://www150.statcan.gc.ca/n1/pub/85-570-x/2006001/findings-resultats/4144393eng.htm

Government of Canada, Statistics Canada (2019). Police resources in Canada, 2018. https://www150.statcan.gc.ca/n1/pub/85-002-x/2019001/article/00015-eng.htm

Greeson, M. R., \& Campbell, R. (2011). Rape survivors' agency within the legal and medical systems: Psychology of Women Quarterly, 35(4), 582-595. https://doi.org/10.1177/0361684311418078

Hill Collins, P., \& Bilge, S. (2016). Intersectionality. Polity Press.

John, N., Casey, S. E., Carino, G., \& McGovern, T. (2020). Lessons never learned: Crisis and gender-based violence. Developing World Bioethics, 20(2), 65-68. https://doi.org/10.1111/dewb.12261

Johnson, I. D., \& Hiller, M. L. (2019). Rural location and relative location: Adding community context to the study of sexual assault survivor time until presentation for medical care. Journal of Interpersonal Violence, 34(14), 2897-2919. https://doi.org/10.1177/0886260516663900

Maier, S. L. (2012). Sexual Assault Nurse Examiners' perceptions of the revictimization of rape victims. Journal of Interpersonal Violence, 27(2), 287-315. https://doi.org/10.1177/0886260511416476

Moylan, C. A., Lindhorst, T., \& Tajima, E. A. (2017). Contested discourses in multidisciplinary Sexual Assault Response Teams (SARTs). Journal of Interpersonal Violence, 32(1), 322. https://doi.org/10.1177/0886260515585530 
Nowell, L. S., Norris, J. M., White, D. E., \& Moules, N. J. (2017). Thematic analysis: Striving to meet the trustworthiness criteria. International Journal of Qualitative Methods, 16(1), 113 https://doi.org/10.1177/1609406917733847

Ontario Hospital Association. (n.d.). Your hospitals. Ontario Hospital Assocation. Retrieved October 21, 2019, from https://www.oha.com/your-hospitals

Ontario Network of Sexual Assault/Domestic Violence Treatment Centres. (n.d.). Get help: Find a centre near you. Ontario Network of Sexual Assault/Domestic Violence Treatment Centres. Retrieved October 21, 2019, from https://www.sadvtreatmentcentres.ca/find-acentre/

Quinlan, A., Fogel, C., \& Quinlan, E. (2009). Unmasking scientific controversies: Forensic DNA analysis in Canadian legal cases of sexual assault. Canadian Woman Studies; Downsview, 28(1), 98-107.

SACHA. (n.d.). SACHA » Statistics. http://sacha.ca/resources/statistics

Shaw, J., Campbell, R., \& Cain, D. (2016). The view from inside the system: How police explain their response to sexual assault. American Journal of Community Psychology, 58(3-4), 446-462. https://doi.org/10.1002/ajcp.12096

Sievers, V., Murphy, S., \& Miller, J. J. (2003). Sexual assault evidence collection more accurate when completed by sexual assault nurse examiners: Colorado’s experience. Journal of Emergency Nursing, 29(6), 511-514. https://doi.org/10.1016/j.jen.2003.08.010

Stermac, L., Dunlap, H., \& Bainbridge, D. (2005). Sexual assault services delivered by SANEs. Journal of Forensic Nursing; Baltimore, 1(3), 124-128. 
Sundler, A. J., Lindberg, E., Nilsson, C., \& Palmér, L. (2019). Qualitative thematic analysis based on descriptive phenomenology. Nursing Open, 6(3), 733-739. https://doi.org/10.1002/nop2.275

Thomas, J. T. (2016). Adverse childhood experiences among MSW students. Journal of Teaching in Social Work, 36(3), 235-255.

https://doi.org/10.1080/08841233.2016.1182609

Ulloa, E., Guzman, M. L., Salazar, M., \& Cala, C. (2016). Posttraumatic growth and sexual violence: A literature review. Journal of Aggression, Maltreatment \& Trauma, 25(3), 286-304. https://doi.org/10.1080/10926771.2015.1079286 